\title{
LA ESCULTURA FUNERARIA DE NICOLÁS GRIEGO TRIARCHI, DEL MUSEO ARQUEOLÓGICO DE SEVILLA (1634)
}

Se documenta la escultura funeraria de Nicolás Griego Triarchi. Procede del extinto Colegio sevillano de San Basilio "el Grande", y fue tallada por el maestro Gaspar Luis en 1634.

Palabras claves: Escultura funeraria; Sevilla; Siglo XVII; Colegio de San Basilio "el Grande"; Entallador; Nicolás Griego Triarchi; Gaspar Luis.

This articule documents the funerary monument of Nicolás Griego Triarchi, sculpted by Gaspar Luis in 1634. Today in the Archaeology Museum, Seville, its original emplacement was the College of Saint Basil "the Great."

Key words: Funerary monument; Sculpture; $17^{\text {th }}$ century; Seville; College of Saint Basil "the Great"; Nicolás Griego Triarchi; Gaspar Luis.

Ubicada en la Galería de salida del Museo Arqueológico de Sevilla, en calidad de depósito, por ser de propiedad municipal, ha sido catalogada oficialmente como obra anónima, por ignorar sus datos de ejecución ${ }^{1}$, llegando incluso a dudarse sobre la persona que representa y errar en uno de sus apellidos, pues en la Guía oficial del Museo se la cita como "la figura yacente de D. Nicolás Griego Ariascho, quizás el fundador en Sevilla de la orden de San Basilio, procedente de la iglesia de Omnium Sanctorum"'. Tampoco Alberto Morales Chacón llega a identificarla en su Escultura funeraria del Renacimiento en Sevilla, al mantener su anonimato y desconocer su cronología, pues la data hacia 1595-16003. Sin embargo, los datos sobre su autoría, costo y fecha de ejecución, fueron dados a conocer en 1928 por el historiador Celestino López Martínez ${ }^{4}$, quien tampoco puso

${ }^{1}$ Así se nos informó al solicitar permiso a la Dirección del Museo para fotografiarla.

2 Museo Arqueológico de Sevilla. Guía oficial. Sevilla: Junta de Andalucía. Consejería de Cultura, 2005, p. 233.

${ }^{3}$ Morales Chacón, Alberto: Escultura funeraria del Renacimiento en Sevilla. Sevilla, 1996, pp. 55-57.

${ }^{4}$ López Martínez, Celestino: Arquitectos, Escultores y Pintores vecinos de Sevilla. Sevilla, 1928, p. 89. 
en relación el documento que publicaba con el bulto funerario, por lo que su aporte quedó para los investigadores como otra noticia más sobre una obra perdida por el paso del tiempo.

Pero no hay dudas para identificar esta escultura, pues se conoce bien el recorrido físico que ha hecho a lo largo de los años, desde su lugar de origen, el extinto convento sevillano de San Basilio, hasta las actuales dependencias museísticas. Desgraciadamente, durante la invasión francesa de la ciudad, muchos de sus conventos sufrieron el pillaje y la ruina parcial, hasta tal punto que su patrimonio artístico se vio mermado drásticamente e incluso sus fábricas quedaron tan resentidas que su recuperación, tras la expulsión del ejército enemigo, fue lenta e incluso imposible, pues las comunidades tuvieron poca tregua, ya que años más tarde las sucesivas desamortizaciones eclesiásticas de 1820-21 y la definitiva de 1835-37, promovidas por el Gobierno $^{5}$, hicieron que abandonaran definitivamente los edificios para servir a otros fines o que se derribaran, pasando parte de sus obras al Estado y el resto a manos privadas. Se sabe que en los años de ocupación francesa los restos y el sepulcro de Nicolás Griego, por su relevancia, se trasladaron a la parroquia de San Miguel, "en la cual estuvieron en un nicho, hasta que por la reconquista de esta ciudad, volvieron los monjes a ocupar su convento". Los basilios no sólo recuperaron parte de su patrimonio artístico, sino que acometieron unas imprescindibles obras de restauración del convento y volvieron a consagrar la iglesia el 13 de junio de 1814. Pero como se ha comentado, sólo permanecerían unas pocas décadas, hasta la exclaustración definitiva de Mendizábal de 1837, aunque el templo siguió sirviendo como sede a la Hermandad de la Santa Cena, allí radicada desde 1621, con algunas temporadas de cierre, hasta que las revueltas cantonales y la amenaza de ruina determinaron su abandono definitivo en $1868^{6}$. En esos momentos el sepulcro debió trasladarse a la inmediata parroquia de Omnium Sanctorum, como recoge José María Tassara, y es la procedencia que se cita en la ficha del Museo Arqueológico ${ }^{7}$.

La memoria de este convento basilio corre pareja a la de Nicolás Griego, pues fue su fundador y constructor, como recoge Diego Ortiz de Zúñiga en sus Anales de Sevilla, al señalar que la presencia de los monjes en Sevilla data del año 1593, fruto de la inquietud de este noble comerciante griego de origen chipriota, vecino de la ciudad y muy acaudalado, que era gran devoto de San Basilio "el Grande" y del "gran olor de santidad" que exhalaban sus integrantes, al mezclar caridad, hondo misticismo y notable cultura. Los hizo venir "con ruegos, beneficios y promesas", concretando la fundación fray Bernardo de la Cruz y otros cuatro monjes que formaron la comunidad inicial, a la que cedió el 9 de enero de ese año sus casas principales en la calle del Relator, en la collación de Omnium Sanctorum, para erigir convento y colegio, comprometiéndose además a sufragar parte de su ajuar litúrgico. A cambio se reservó el patronato sobre la fundación y el derecho a enterrarse en su capilla mayor. Ese provechoso convenio fue ratificado por el Provincial fray Baltasar Ramírez de San Ildefonso, aprobado por Bula de Clemente VIII ese mismo año, y llevado el 28 de septiembre de 1594 al Provisor y Vicario general del Arzobispado, que concedió la licencia de radicación ${ }^{8}$.

El inmueble, de fisonomía mudéjar, sería objeto de mínimas obras de reacomodo para tan pocos ocupantes, una precariedad que se resolvería un año más tarde ya que el comerciante se obligó, por su testamento de 20 de abril de 1594, a levantar una capacitada iglesia, y a costear el retablo mayor y su sepulcro, "con otras dotaciones", instituyendo como heredero universal al Hospital de la Misericordia, del que era hermano, con la obligación de constituir, tras su fallecimiento, un

\footnotetext{
5 Sobre estas desamortizaciones véase MANUEL CASTELLS, José: Las asociaciones religiosas en la España contemporánea. Un estudio jurídico-administrativo (1767-1965). Madrid, 1973, pp. 118-147.

${ }^{6}$ Carrero Rodríguez, Juan: Anales de las Cofradias Sevillanas. Sevilla, 1984, p. 71.

7 Morales Chacón, Alberto: Escultura funeraria... ob. cit., p. 56.

${ }^{8}$ Ortiz de ZúÑIgA, Diego: Anales eclesiásticos y seculares de la Muy Noble y Muy Leal Ciudad de Sevilla. T. IV. Madrid, 1796, reimp. Sevilla, 1988, p. 155.
} 
patronato para cumplir su última voluntad ${ }^{9}$. Con los años, otras mandas funerarias aseguraron la existencia del Colegio conventual, llegando los basilios a poseer varias casas en los alrededores ${ }^{10}$, contando en su templo con populosas hermandades, como la de la Cena y la Macarena. Podemos hacernos una idea de la disposición y aspecto del conjunto, aparte de por las palabras de Zúñiga: "La iglesia, aunque mediana, es bien labrada, completos los claustros y habitación", por la descripción que en 1839 y 1844 realizó Félix González de León, que llegó a verlo en su integridad; por el Plano de Sevilla levantado en 1771 por orden del Asistente de la ciudad Pablo de Olavide; y por los escasos restos materiales aún conservados, que afloran en catas arqueológicas. Ocupaba el extremo sur de la manzana orillada por la calle del Relator, que era un tramo algo corto que nacía en la calle Escuderos -actual Cristo de la Sentencia- y llegaba sólo a Parras o hasta la Cruz de la Caja o Huerto de la Caja según las épocas, y que no era sino una prolongación de una calle bastante alargada y rectilínea que partía de la Alameda de Hércules, llamada Honda por estar a nivel más bajo, hoy también Relator, y que en esos metros pasó a llamarse de San Basilio por tener en uno de sus lados la iglesia. A esa calle abría la fachada de los pies y al parecer el convento, mientras que la trasera del claustro llegaba hasta la de Parras, a la de Torres otro brazo claustral y al parecer un atrio de entrada, y a la calle Escuderos, que se llamó Dormitorio de San Basilio, otra de esas galerías y parte de los dormitorios, pues el resto de la manzana, limitada al norte por la calle Huerto de la calle Linos, ahora Escoberos, se encontraba sin urbanizar, dedicada a huertas y para artesanías que necesitasen de suficiente terreno y agua ${ }^{11}$ (fig. 1).

Con respecto al patrimonio artístico que llegó a poseer este austero convento, pocas son las piezas documentadas pues, aparte del sepulcro de su benefactor, sólo se han publicado datos sobre su retablo mayor, pintado entre 1638 y 1639 por el maestro de la escuela pictórica sevillana del barroco Francisco de Herrera "el Viejo". Su valía fue dada a conocer tempranamente a la historiografía y a las apetencias expoliatorias por el neoclásico Ponz en 1791'2; recogida por Ceán Bermúdez en $1800^{13}$; y finalmente ratificada su autoría en 1928 por López Martínez ${ }^{14}$. Afortunadamente se conservan en el Museo de Bellas Artes sevillano varios de sus lienzos ${ }^{15}$. Aparte, son escasas las referencias que se tienen del resto de obras, posteriores a la exclaustración de la comunidad, ya que únicamente contamos con la descripción de González de León de 1839 y 1844 , cuando todavía seguía abierto el templo.

En cuanto a la ejecución del sepulcro funerario de Nicolás Griego, a pesar de dejar ordenado en 1594 su ejecución y la del retablo, su hechura se retrasó 40 y 44 años respectivamente. De mármol, fue encargado en 1634 al maestro Gaspar Luis, un virtuoso entallador especializado en la labra de ese material que vivía en unas casas fronteras al colegio dominico hispalense de Santo Tomás de Aquino, en el barrio de Santa María, del que hemos documentado otras interven-

\footnotetext{
9 Ibidem T. V, p. 54.

10 Ollero Lobato, Francisco: Noticias de arquitectura (1761-1780). Sevilla, 1994, pp. 241-242. Prieto GordiLlo, Juan: Noticias de escultura (1761-1780). Sevilla, 1995, p. 140.

11 GonZÁlez de León, Félix: Noticia histórica del origen de los nombres de las calles de esta M. N. M. L. y M. H. Ciudad de Sevilla. Sevilla, 1839, pp. 184, 203-204, 354, 386-387, 414, 440-441. Collantes DE Terán, Antonio y otros: Diccionario histórico de las calles de Sevilla. Sevilla, 1993, T. I, pp. 326-327, T. II, pp. 179, 254-255, 418. MenA, José María de: Las calles de Sevilla. Sevilla, 1973, pp. 101-102, 203.

12 Ponz, Antonio: Viage de España en que se da noticia de las cosas más apreciables y dignas de saberse, que hay en ella. Madrid, 1792, t. IX, carta 3. a, reed. Sevilla, 2001, pp. 82-83.

13 CeÁn Bermúdez, Juan Agustín: Diccionario histórico de los más ilustres profesores de las Bellas Artes en España. Madrid, 1800, reimp. Madrid, 2001, t. II, p. 278, t. VI, pp. 21-22.

14 López Martínez, Celestino: Arquitectos, Escultores... ob. cit., pp. 65-67, 163-165.

15 Martínez Ripoll, Antonio: Francisco de Herrera "el Viejo". Sevilla, 1978, pp. 34-35, 111-119, figs. 64-73. Valdivieso GonzÁlez, Enrique: La pintura en el Museo de Bellas Artes de Sevilla. Sevilla, 1993, pp. 144-147, láms. 151-155. Del mismo autor: Historia de la pintura sevillana. Siglos XIII al XX. Sevilla, 1992, pp. 165, 167, lám. 127.
} 


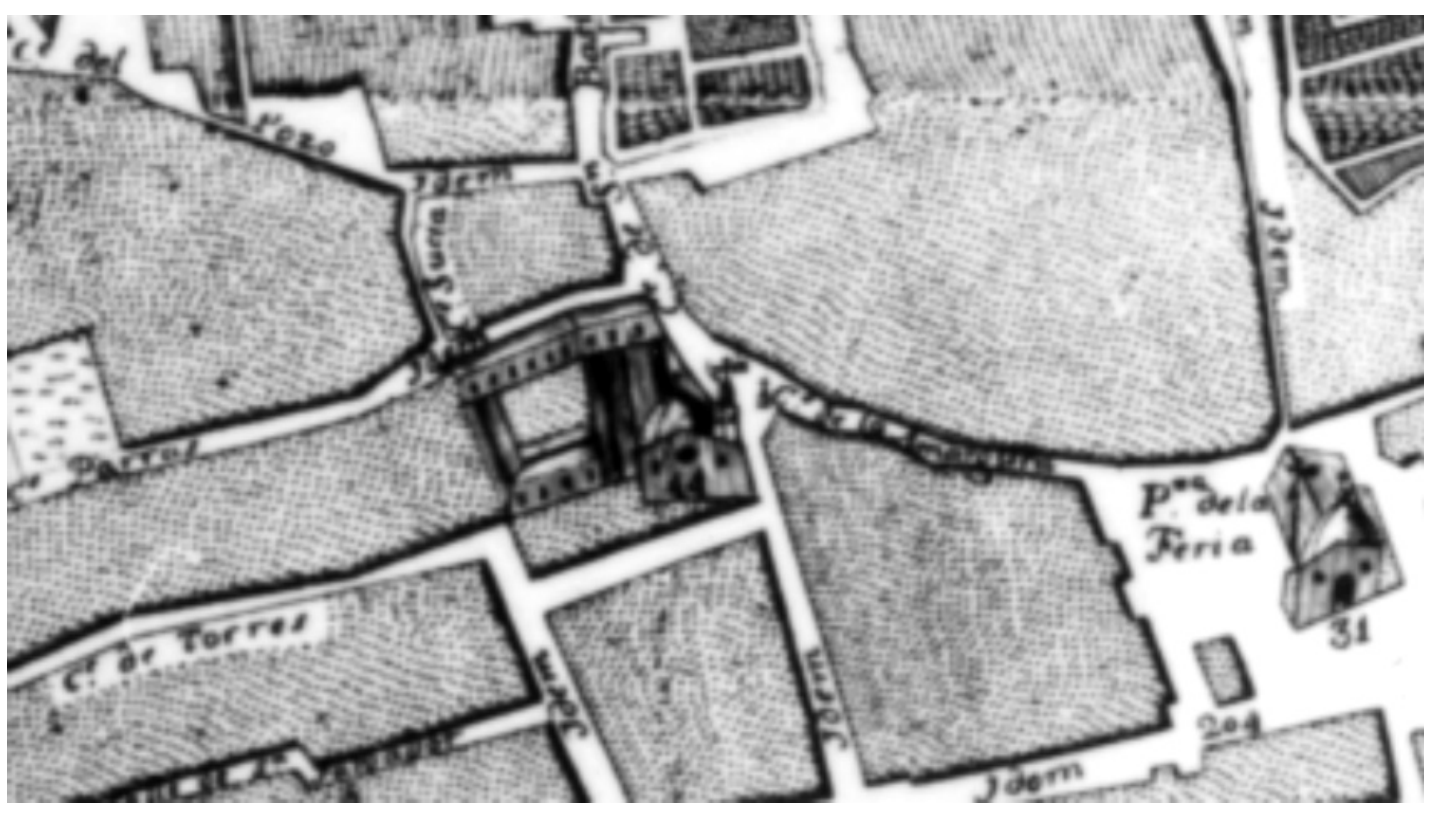

Fig. 1. Situación del colegio de San Basilio según el plano de Olavide (n. $\left.{ }^{\circ} 44\right)$.

ciones $^{16}$. El concierto se llevó con un representante del Hospital de la Misericordia, su tesorero Francisco de Ocaña, en precio de 400 ducados (4.400 reales), de los cuales recibió como finiquito la mitad, 2.200 reales, el 27 de mayo de ese año, una vez acabado y asentado a contento de la comunidad. Debió responder a la tipología de arco solio, que se adosa a la pared, en el rehundimiento creado por un medio punto que evita estorbo a los presbíteros, pues se colocó en uno de los colaterales de la capilla mayor, y además este modelo era refrendo de durabilidad, ya que evitaba las roturas por fricción involuntaria ${ }^{17}$. En la documentación se especifica que el difunto se representaría yacente sobre una cama, apoyando la cabeza en un cojín y vestido con noble indumentaria, sobre una "urna y leones", haciendo alusión al pedestal, que sería un paralelepípedo de paredes rectas cargado sobre esos feroces animales esquineros, fieles guardianes hasta la llegada del Juicio Final, y símbolo del león fuerte de Judá, que lo es de Cristo, que espera pacientemente el momento con los ojos abiertos. Se colocó antes del 6 de mayo, pues en esa fecha lo inspeccionó el maestro mayor de obras de la ciudad Marcos de Soto, que determinó se podía finiquitar por estar "en toda perfección"18 (fig. 2). Sobre la fría cama, que tiene tallado sólo uno de sus lados mayores, por responder a la tipología de hornacina, la figura de Nicolás Griego muestra una gran quietud, simetría y recogimiento, con un rostro idealizado, en el instante

${ }^{16}$ Como la restauración de cantería en 1648 de la fuente de Mercurio de la plaza sevillana de San Francisco, en piedra martelilla malagueña, que contrató por 2.000 reales, según las trazas del maestro mayor de la ciudad Pedro Sánchez Falconete. Cruz Isidoro, Fernando: Arquitectura Sevillana del Siglo XVII. Maestros Mayores de la Catedral y del Concejo Hispalense. Sevilla, 1997, p. 238. Del mismo autor: El arquitecto sevillano Pedro Sánchez Falconete. Sevilla, 1991, pp. 68-69.

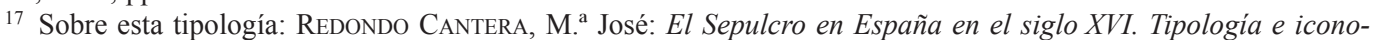
grafia. Madrid, 1987.

${ }^{18}$ López Martínez, Celestino: Arquitectos, Escultores,... ob. cit., p. 89. Cruz Isidoro, Fernando: Arquitectura Sevillana del Siglo XVII... ob. cit., p. 221. 


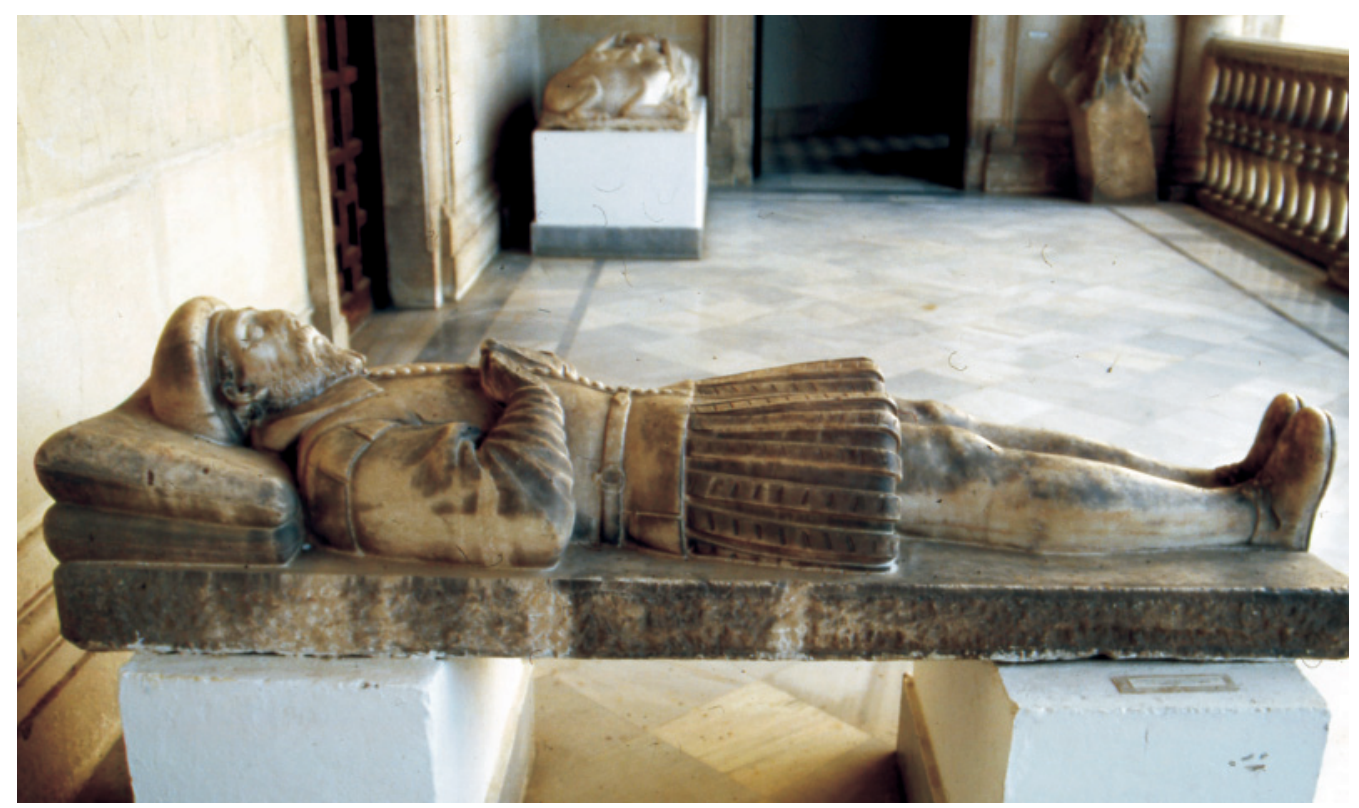

Fig. 2. Escultura funeraria de Nicolás Griego Triarchi. Galería de Salida del Museo Arqueológico de Sevilla. Por cortesía de la Consejería de Cultura de la Junta de Andalucía y del propio Museo.

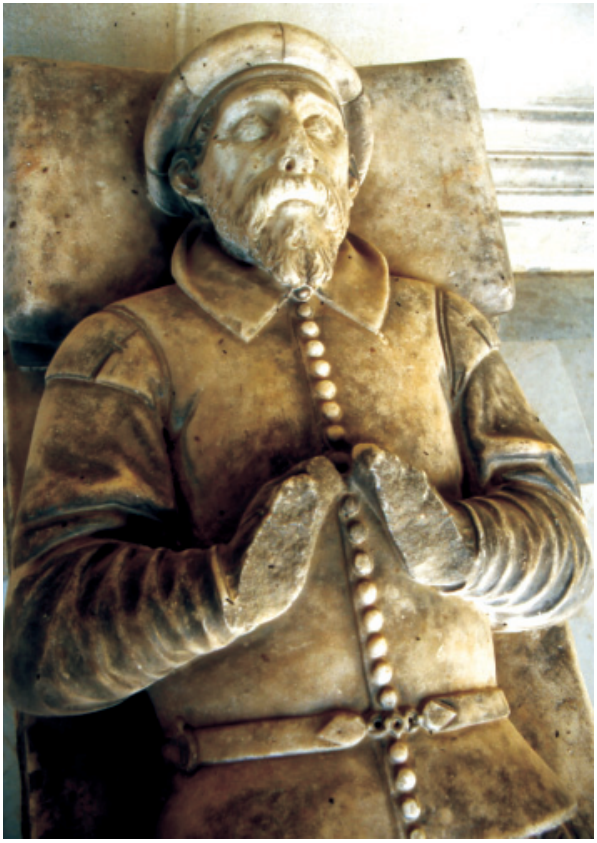

Fig. 3. Detalle de la Fig. 2.

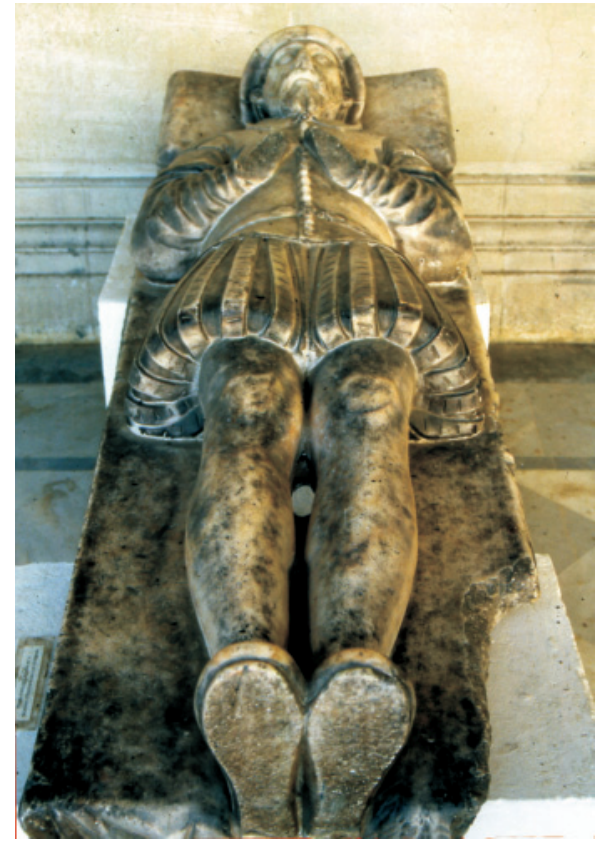

Fig. 4. Detalle de la Fig. 2. 
del sueño eterno, con los ojos apenas cerrados, ya que por el tiempo transcurrido no cabía un verdadero retrato ni se hace alusión al empleo de una mascarilla funeraria, que no tiene lugar con una persona que no ha muerto en olor de santidad, pues lo que se pretende es simplemente representar su status social, de ahí su faz noble y clásica, de poblado bigote y barba bífida (fig. 3). Los brazos se pegan al cuerpo, descansando las manos, perdidas, sobre el pecho, y vestido a la manera de los ricos comerciantes de principios del XVII, con camisa de cuello de pico abotonada, calzas acuchilladas que se ciñen con cinturón con hebilla, gorra de paño gallonado en forma de capacete, y zapatillas acordonadas (fig. 4).

FERNANDO CRUZ ISIDORO Universidad de Sevilla 